\title{
Protective effects of cholestyramine on liver cirrhosis induced by carbon tetrachloride in the rat
}

\author{
K DE HEER, H-D SAUER, B WERNER, AND G KLOEPPEL \\ From the Department of General Surgery and Institute of Pathology, University Hospital Hamburg, \\ Hamburg, Federal Republic of Germany
}

SUMMARY The influence of cholestyramine and chenodeoxycholic acid on the induction of liver cirrhosis by carbon tetrachloride was investigated in the Wistar rat. The addition of $1.3 \%$ cholestyramine to the diet of the experimental animals inhibited to a large extent the induction of cirrhosis. While all the animals subjected to carbon tetrachloride exposure plus basal diet and those to carbon tetrachloride intoxication plus chenodeoxycholic acid diet developed cirrhosis, the morphological manifestation of cirrhosis occurred in the livers of only two out of 18 rats under carbon tetrachloride treatment plus cholestyramine diet. The administration of cholestyramine induces reactions which correspond to the physiological protective mechanisms of the liver. These are the bile acid binding, bacteriostatic, and microsomal enzymatic stimulating properties of cholestyramine.

The central role of the liver in metabolism of the bile acids includes the synthesis, conjugation, and the maintenance of the integrity of the enterohepatic circulation. The control of the size and composition of the bile acid pool and the detoxification of noxious intermediate products from the intestinal tract is modified and regulated by the hepatocytes. These functions are more or less impaired during cirrhosis or other diseases of the liver. Consequently the toxic bile acids, especially the secondary bile acids, lithocholic and deoxycholic acids, in the enterohepatic circulation are not detoxified. ${ }^{1-3}$ Whether the disturbed bile acid metabolism has an influence on the impaired liver has only been investigated to a limited extent.

Furthermore, the pathogenic effects of several intermediate products of bile acid metabolism have been experimentally verified. ${ }^{4-8}$ Thus Holsti induced liver cirrhosis in the rabbit by oral administration of desiccated whole bile preparation ${ }^{9}$ and by gastric instillation of lithocholic acid. ${ }^{10}$

The question that particularly interests us, therefore, is whether the oral application of chenodeoxycholic acid (CDCA), the main source of lithocholic acid, and cholestyramine (CT), a quaternary ammonium anion exchange resin, which has a strong affinity for bile salts in the intestine and thus prevents their enteral resorption, has an influence on

Received for publication 13 May 1980 the induction of cirrhosis by carbon tetrachloride $\left(\mathrm{CCl}_{4}\right)$ in the rat.

\section{Methods}

\section{ANIMALS}

Four week old male Wistar rats weighing between 200 and $300 \mathrm{~g}$ were obtained from the Deutsche Versuchstieranstalt, Hannover, West Germany. Four animals were kept in a cage in a room with a daily cycle of alternating 12 hour periods of light and darkness.

\section{DIET}

The animals were maintained on a special diet obtained from the firm Dr R Scholt in Hamburg, West Germany: (1) chenodeoxycholic acid diet: $300 \mathrm{~g}$ basal diet was supplemented with $1 \mathrm{~g}$ CDCA; (2) cholestyramine diet: $300 \mathrm{~g}$ basal diet was supplemented with $4 \mathrm{~g}$ cholestyramine; (3) control diet consisted of basal diet without supplement.

\section{ANIMAL GROUPS}

The following groups were formed.

Group I

Twenty animals fed on the basal diet were treated with $\mathrm{CCl}_{4}$.

Group II

Twenty animals fed on the cholestyramine diet were treated with $\mathrm{CCl}_{4}$. 


\section{Group III}

Twenty animals fed on the cholestyramine diet were treated with $\mathrm{CCl}_{4}$.

Group IV

Five animals were allowed the basal diet and tap water but were not treated with $\mathrm{CCl}_{4}$.

DRINKING WATER

Sodium phenobarbitone was dissolved in tap water at a concentration of $0.5 \mathrm{~g} / \mathrm{l}$. This was the only drinking water available to the animals in groups I, II, and III.

\section{INDUCTION OF CIRRHOSIS}

The induction of cirrhosis in the experimental animals was carried out according to the method of McLean et al. ${ }^{11}$ The animals in groups I, II, and III were placed in a wooden box with a glass front for 20 minutes twice a week. Oxygen was passed through a flowmeter at $21 / \mathrm{min}$, bubbling through a train of two wash-bottles containing $\mathrm{CCl}_{4}$ maintained at $20^{\circ} \mathrm{C}$, into the box. $\mathrm{CCl}_{4}$ was blown in for $10 \mathrm{~min}$ - utes and the rats then left in the inhalation chamber for an additional 10 minutes. The $\mathrm{CCl}_{4}$ treatment was curtailed after 10 weeks. During the experimental period the animals were weighed every two weeks.

\section{NECROPSY AND HISTOLOGY}

Sixteen weeks after the first $\mathrm{CCl}_{4}$ exposure the animals were killed and dissected. The liver was removed in toto and fixed in $3.5 \%$ formalin. For the histological slides $5 \mu$ thick paraffin slices were prepared and stained with haematoxylin and eosin and PAS alternately.

\section{Results}

During the $\mathrm{CCl}_{4}$ administration five animals from group I, four in group II, and two in group III died. These were not considered in the final evaluation of the results. The weight measurement showed no significant differences between the various groups. Only the control group steadily gained weight.

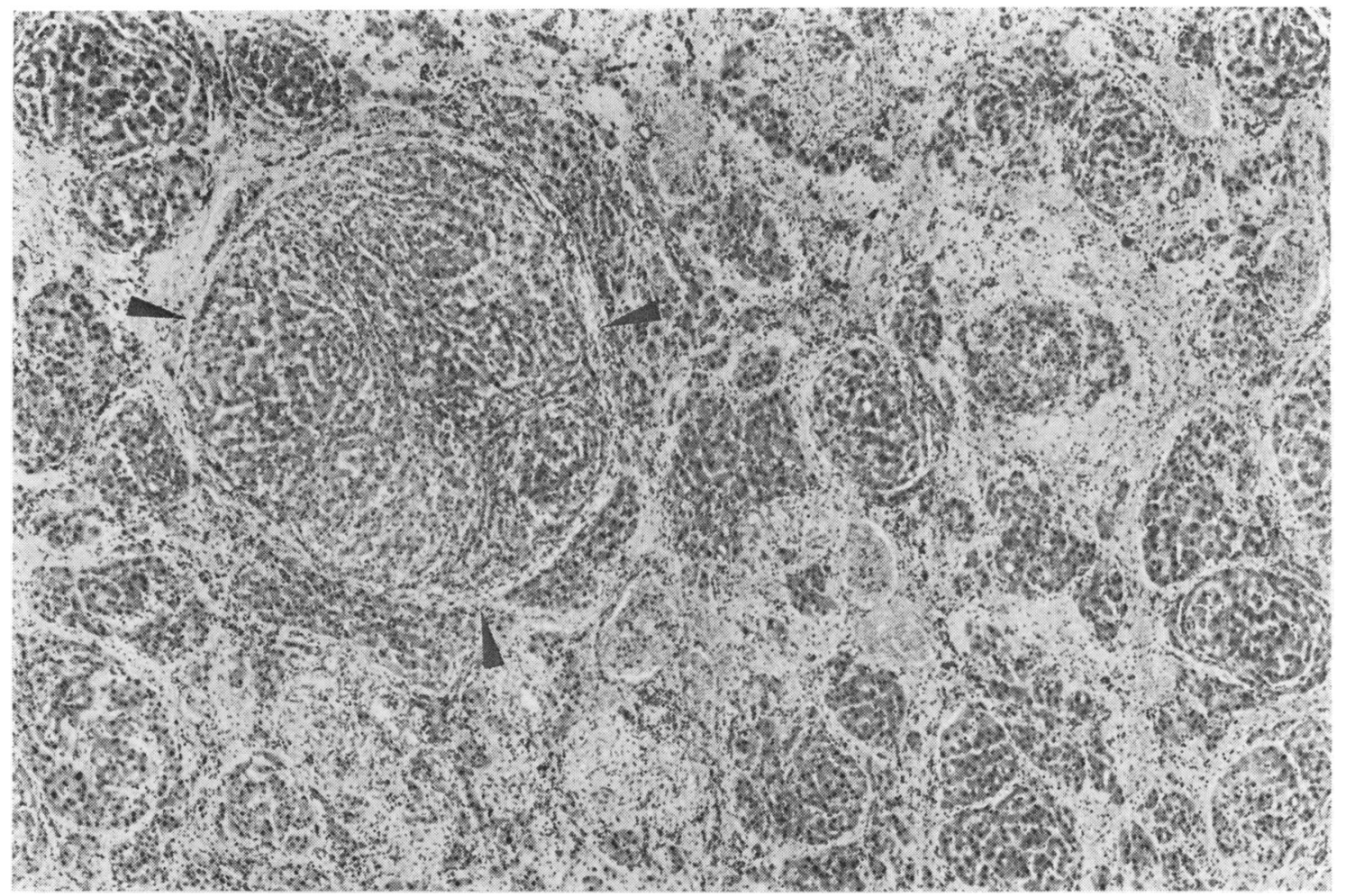

Fig. 1 Rat liver after $\mathrm{CCl}_{4}$ exposure: cirrhosis with complete destruction of normal architecture and the formation of regeneration nodules (arrow). PAS, $\times 84$. (Original magnifications are given in this and the following figures.) 
MACROSCOPIC FINDINGS

In all the animals in group I (only $\mathrm{CCl}_{4}$ treatment) and group II $\left(\mathrm{CCl}_{4}\right.$ treatment plus CDCA diet) the liver had a fine nodular surface and a firm consistency, while most of the animals in group III $\left(\mathrm{CCl}_{4}\right.$ treatment plus CT diet) had livers with a smooth surface and normal consistency. Only two of 18 animals in this group had livers with a fine nodular surface and firm consistency.

\section{MICROSCOPIC FINDINGS}

In group I (only $\mathrm{CCl}_{4}$ treatment) and group II $\left(\mathrm{CCl}_{4}\right.$ treatment plus CDCA diet) a complete cirrhosis developed in all the animals (Table). The cirrhosis was highly active in the majority of the animals. Regeneration nodules of varying sizes and remnants of the original liver lobules were seen between broad scars and thinner connective tissue septa which were infiltrated mostly with histiocytes (Fig 1). In some livers the cirrhosis was less obvious, the parenchyma being irregularly separated by thin strands of connective tissue. These septa were scantily infiltrated with histiocytes (Fig. 2) There was no cholestasis.
Table Histological findings in the various groups

\begin{tabular}{|c|c|c|c|c|c|}
\hline \multirow[t]{2}{*}{ Group } & \multirow[t]{2}{*}{$N$} & \multirow[t]{2}{*}{ Cirrhosis } & \multicolumn{2}{|l|}{ Fibrosis } & \multirow{2}{*}{$\begin{array}{l}\text { Normal } \\
\text { tissue }\end{array}$} \\
\hline & & & Marked & Slight & \\
\hline I & & & & & \\
\hline $\begin{array}{l}\left.\text { (CC }{ }_{\text {II }} \text {-exposure }\right) \\
\text { (a) }\end{array}$ & 15 & 15 & & & \\
\hline $\begin{array}{l}\left(\mathrm{CCl}_{4}+\mathrm{CDCA}\right) \\
\text { III }\end{array}$ & 16 & 16 & & & \\
\hline $\begin{array}{l}\left(\mathrm{CCl}_{4}+\mathrm{CT}\right) \\
\mathrm{IV}\end{array}$ & 18 & 2 & 4 & 12 & \\
\hline (control group) & 5 & & & & 5 \\
\hline
\end{tabular}

CDCA : Chenodeoxycholic acid.

CT: cholestyramine.

A comparison of the histological pictures of the liver in group I (only $\mathrm{CCl}_{4}$ treatment) and group II $\left(\mathrm{CCl}_{4}\right.$ treatment plus CDCA diet) showed that in group II the condensation of fibrous septa and the infiltration with histiocytes were more pronounced than in the group $\mathrm{I}$.

In group III $\left(\mathrm{CCl}_{4}\right.$ treatment plus $\mathrm{CT}$ diet $)$ one animal developed a complete cirrhosis with mild activity. In another animal only parts of the liver showed nodularity, while the other parts displayed a

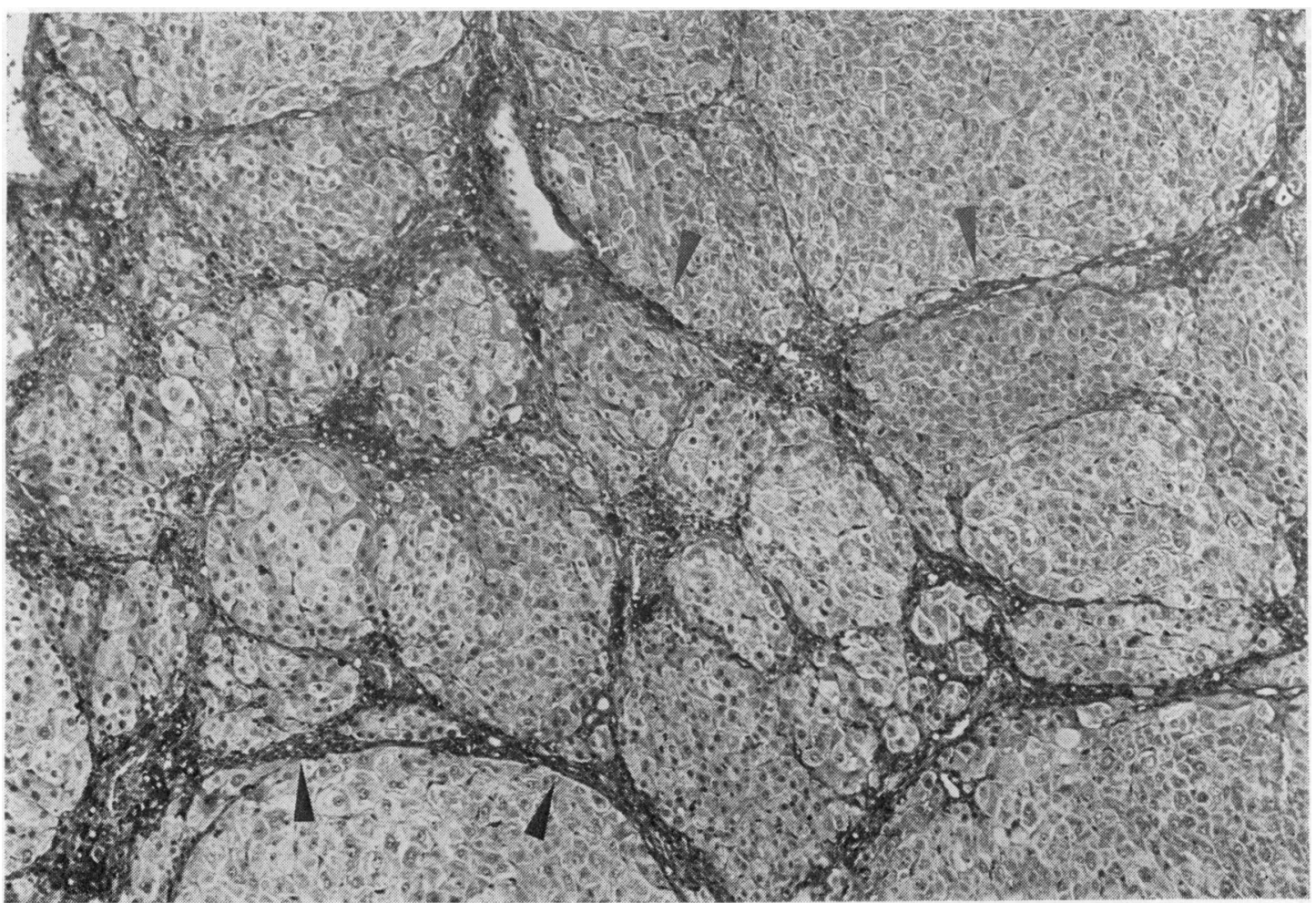

Fig. 2 Rat liver after $\mathrm{CCl}_{4}$ exposure and chenodeoxycholic acid administration: cirrhosis with irregular separation of the liver parenchyma by strands of connective tissue (arrows). PAS, $\times 196$. 


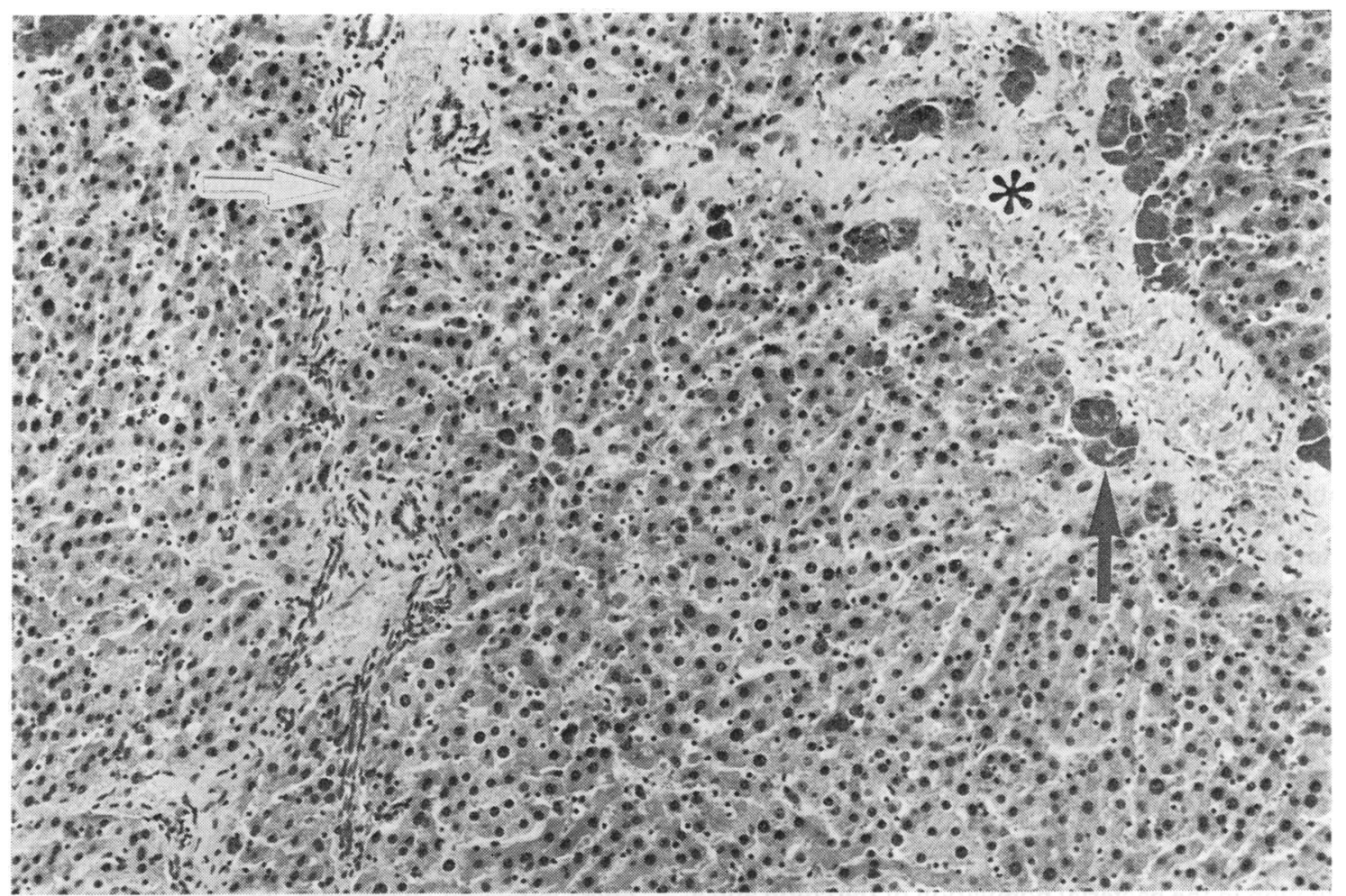

Fig. 3 Rat liver after $\mathrm{CCl}_{4}$ exposure and cholestyramine dietary supplement: liver tissue with fibrotic changes but persisting basic architecture. Moderate fibrosis is seen in the portal field (white arrow) and the centrilobular area (asterisk). Groups of PAS-positive histiocytes at the margin of the centrilobular fibrosis (black arrow). $P A S, \times 196$.

distinctive fibrosis of the portal tracts and centrilobular areas (incomplete cirrhosis). In contrast, only fibrotic but no cirrhotic changes were found in the remaining 16 animals. The fibrosis developed in the portal and centrilobular areas (Fig. 3) and was of varying intensity. It was marked in four animals and slight in 12 animals (Table). Within the centrilobular scars and the adjacent parenchyma there were groups of histiocytes laden with ceroid pigment, a consequence of single hepatocyte necrosis (Fig. 3). The hepatocytes showed distinct anisokaryosis of the nuclei. Bile duct proliferation was lacking. In the untreated animals (group IV) no pathological changes were found.

\section{Discussion}

The most important result of this experimental study is the fact that the induction of liver cirrhosis by carbon tetrachloride in the rat is strongly modified by simultaneous administration of $1.3 \%$ cholestyra- mine. Only two out of 18 animals developed cirrhosis of the liver, while the remaining 16 showed scantily distributed single hepatocyte necrosis with mild centrilobular cicatrisation.

Under physiological conditions the toxic lithocholic acid is formed by 7-alpha bacterial dehydroxylation of chenodeocholate in the intestine (usually in the colon and terminal ileum). Because of poor absorption only part of the lithocholate reaches the liver via the enterohepatic circulation. An important aspect of the lithocholate detoxification which occurs mainly in the liver in humans and in the rat is esterification with sulphate. ${ }^{2}$ Furthermore, the intact liver has the ability to convert lithocholate into the non-toxic hyodeoxycholic acid. ${ }^{12}$ This physiological detoxification process is catalysed by the enzymes 7-alpha and 12-alpha hydroxylase. ${ }^{13}$ With impairment of liver functions, clinically by cirrhosis and experimentally by $\mathrm{CCl}_{4}$ intoxication, the detoxification of lithocholic acid is more or less retarded. Because of severe liver damage a relative deficiency of 12-alpha hydroxylase activity develops resulting 
in an increased formation of chenodeoxycholic acid instead of cholic acid, which is transformed by colonic bacteria into lithocholic acid. ${ }^{5}$

The liver damage in the experimental animals caused by $\mathrm{CCl}_{4}$ inhalation consists of a partial parenchymal necrosis and a consequent reduction in the microsomal enzymatic activity. Because in the rat $80 \%$ of bile acids are located in the microsomes, ${ }^{14}$ the hydroxylation reactions which take place in these organelles are further impeded. Changes in optical absorption spectra produced by addition of $\mathrm{CCl}_{4}$ to microsomes suggest a close attachment of $\mathrm{CCl}_{4}$ to cytochrome P450. ${ }^{15}$ Similarly, bile salts are known to interact with microsomal elements, specially cytochrom P450. It is, therefore, conceivable that the simultaneous administration of $\mathrm{CCl}_{4}$ and CDCA causes an increased inhibition of cytochrome P450. The inhibition of cytochrome P450 leads to increased formation of lithocholate directly from cholesterol or indirectly via dehydroxylation of chenodeoxycholate in the enterohepatic circulation. ${ }^{16}$

The cytotoxic effects of bile salts are related to their amphipatic properties and involves interaction with membranes and organelles. The incorporation with lysosomes plays an especially important role in causing tissue injury. ${ }^{17} 18$

Cholestyramine, which has a strong affinity for bile acids and bacteriostatic effects, causes a reduction in the bacterial population of the colon and a sequestration of primary bile salts preventing it from biotransformation into lithocholate ${ }^{19}$ Consequently, less lithocholate is produced after cholestyramine administration. In addition, this bile acid binding resin stimulates the enzymes 7-alpha and 12-alpha hydroxylases, ${ }^{13}$ a deficiency of the latter leads to increased serum lithocholic acid concentrations which perpetuate liver injury. ${ }^{5}$

Studies on the effects of carbon monoxide on hydroxylation in the biosynthesis and metabolism of bile acids have revealed that the 12 -alpha hydroxylation may not involve a cytochrome P450, a carbonmonoxide sensitive haemoprotein. ${ }^{13}$ This is an indication that the stimulation of 12-alpha hydroxylation after cholestyramine does not lead to an alteration of the levels of cytochrome P450. Thus, when $\mathrm{CCl}_{4}$ and cholestyramine are simultaneously administered, the latter causes an increase in the activity of microsomal hydroxylation reactions but leaves the level of microsomal cytochrome P450 unchanged. The resulting condition maintains other microsomal oxidative reactions to a considerable extent, compared with the group treated with $\mathrm{CCl}_{4}$ alone. Whether these effects of cholestyramine reduce the damage caused by $\mathrm{CCl}_{4}$ intoxication or repair the damage afterwards merits additional investigation.
It is, therefore, possible that, through the administration of cholestyramine, mechanisms are triggered which correspond to the physiological protective reactions of the liver. This could explain the effect of cholestyramine in modifying the liver cirrhosis induced by carbon tetrachloride.

\section{References}

${ }^{1}$ Vlahcevic ZR, Buhac I, Bell CC Jr, Swell L. Abnormal metabolism of secondary bile acids in patients with cirrhosis. Gut 1970; 11: 420-2.

${ }^{2}$ Palmer RH. Bile acids sulfates. II. Formation, metabolism and excretion of lithocholic acid sulfates in the rat. J Lipid Res 1971 ; 12 : 680-7.

${ }^{3}$ Vlahcevic ZR, Prugh MF, Gregory DH, Swell L. Disturbances of bile acid metabolism in parenchymal liver cell disease. Clin Gastroenterol 1977; 6: 1, 25-43.

${ }^{4}$ Cook JW, Kennaway EL, Kennaway NM. Production of tumours in mice by deoxycholic acid (letter). Nature (Lond) 1940; 145 : 627.

${ }^{5}$ Carey JB Jr, Wilson ID, Onstad G, Zaki FG. Role of $12 \alpha$ hydroxylase deficiency in continuing liver injury (abstract). J Clin Invest 1967; 46: 1042-3.

${ }^{6}$ Davenport HW. Destruction of the gastric mucosal barrier by detergents and urea. Gastroenterology 1968; 54: 175-81.

'Narisawa T, Magadia NE, Weisburger JH, Wynder EL. Promoting effect of bile acids on colon carcinogenesis after intrarectal instillation of $\mathrm{N}$-methyl- $\mathrm{N}^{\prime}$-nitronitroso-guanidine in rats. J Natl Cancer Inst 1974; 53: 1093-7.

${ }^{8}$ Werner B, de Heer K, Mitschke H. Cholecystectomy and carcinoma of the colon. An experimental study. Krebsforsch 1977; 88: 223-30.

${ }^{9}$ Holsti P. Experimental cirrhosis of the liver in rabbits induced by gastric instillation of desiccated whole bile. Acta Pathol Microbiol Scand (A) suppl. 1956; 112: 1-67.

${ }^{10}$ Holsti P. Cirrhosis of the liver induced in rabbits by gastric instillation of 3-monohydroxycholanic acid. (Letter) Nature 1960; 186: 250.

${ }^{1 M c L e a n ~ E K, ~ M c L e a n ~ A E M, ~ S u t t o n ~ P M . ~ I n s t a n t ~}$ cirrhosis. An improved method for producing cirrhosis of the liver in rats by simultaneous administration of carbon tetrachloride and phenobarbitone. $\mathrm{Br} J$ Exp Pathol 1969; 50: 502-6.

${ }^{12}$ Einarsson $\mathrm{K}$. On the formation of hyodeoxycholic acid in the rat. J Biol Chem 1966; 241 : 534-9.

${ }^{13}$ Johannson G. Effect of cholestyramine and diet on hydroxylations in the biosynthesis and metabolism of bile acids. Eur J Biochem 1970; 17 : 292-5.

${ }^{14}$ Leuschner U, Alfurayh A, Uhlmann W, Wild-Grube HJ, Erb W. Untersuchungen zur Lokalisation von Gallensäuren in der Leberzelle. Gastroenterol 1974; 12: 95-102.

${ }^{15}$ Garner RC, McLean AEM. Increased susceptibility to carbon tetrachloride poisoning in the rat after pretreatment with oral phenobarbitone. Biochem Pharmacol 1969; 18 : 645-50. 
${ }^{16}$ Palmer RH. Bile acids, liver injury, and liver disease. Arch Intern Med 1972; 130: 606-17.

${ }^{17}$ Weissmann G. Studies of lysosomes. VI. The effect of neutral steroids and bile acids on lysosomes in vitro. Biochem Pharmacol 1965; 14: 525-35.
${ }^{18}$ Weissmann G. The role of lysosomes in inflammation and disease. Ann Rev Med 1967; 18:97-112.

${ }^{19}$ Williams RC, Showalter R, Kern F Jr. In vivo effect of bile salts and cholestyramine on intestinal anaerobic bacteria. Gastroenterology 1975; 69: 483-91. 